\title{
KNOWLEDGE AND PRACTICE OF LADY HEALTH VISITORS REGARDING CERVICAL CANCER IN PUBLIC SECTOR MATERNALAND CHILD HEALTH CENTERS IN LAHORE, PAKISTAN
}

\author{
Noreen Zafar ${ }^{1}$, Anam Zahira ${ }^{2}$, Moeen ud din ${ }^{3}$, Iffat $\mathrm{Naz}^{4}$, Anwar Choudhary ${ }^{5}$ and Saleem M Rana ${ }^{6}$
}

${ }^{1}$ Consultant Gynecologist, Doctors Hospital Lahore,

${ }^{2}$ Medical Officer SGRH Lahore

${ }^{3}$ Assistant Registrar, Contech School of Public Health Lahore

${ }^{4}$ Assistant Professor, Contech School of Public Health Lahore

${ }^{5}$ Director, Medical Education, IPH, Lahore

${ }^{6}$ Professor, Contech School of Public Health Lahore

Correspondence: Saleem M Rana, Email, saleem.rana@contech.org.pk, Cell: 03004335628

\begin{abstract}
Background: Globally cancer has grown as public health issue in developing and developed countries, especially swiftly spreading in low income areas because there are inadequate means for prevention, diagnosis and treatment.

Methods: A hospital based cross-sectional research study was conducted from 11th December to 31st, 2016. There are total 52 centers in Lahore are working to provide the basic $\mathrm{MCH}$ health services in the community headed by Lady Heath Visitors. Hence; all Lady Heath Visitors were selected to participate in the study and were interviewed at their center by a trained research associate.

Results: All respondents had basic knowledge about cervical cancer. 96.1\% respondents were aware about speculums used in gynecology examination, and rests were not aware. $94.2 \%$ were familiar with indication of cervical cancer, $92.3 \%$ were aware about indication for doing a speculum examination and $82.7 \%$ told that they were able to diagnose cervical cancer in routine gynecological examination and same percentage reported that they had been taught how to do speculum examination.
\end{abstract}

Conclusion: Majority of staff had insufficient knowledge regarding cervical cancer prevalence, treatment and prevention. Practices of the health providers were not up to minimum standard of any basic health services.

Keywords: Cervical cancer, knowledge, maternal and child health, lahore

\section{Introduction}

Cancer is rapidly spreading in the world especially in low income countries (1). Cervical cancer is cancer of cervix (2). Cervical cancer causes due to abnormal growth of cervix cells which spreads in to other body parts (3). Initially there are no typical symptoms, later starts pelvic pain, vaginal bleeding and pain during intercourse(4). In $90 \%$ cases papillomavirus (HPV) caused this cancer(5,6,7). Smoking, weak immune system birth control pills sex in very young age, multiple sex partners are also significant causes of cervical cancer. $(1,3)$.For diagnosis there are cervical screening, biopsy, imaging etc. are methods(1).

HPV vaccination can prevent $90 \%$ cervical cancer $(8,9,10,11)$. Pap smear or acetic acid can Cervical cancer screening using the Pap smear or acetic acid can detect precancerous changes and diagnose well in time (12). Surgery, chemotherapy and radiotherapy are available for cancer treatments. There are nearly $8 \%$ of total cases die due to this cancer (13).

Prognosis of cervical cancer depends on how early cancer is Outcomes depend very much on how early the cancer is distinguished. 528,000 cervical cancer cases were globally detected in 2012 and 266,000 died among them, $70 \%$ were notified from developing countries. Cancer deaths are most common cause in the low income countries (10). Cervical cancer incidence has been reduced dramatically in developed countries due to screening programmes for early diagnosis and prompt treatment $(14,15)$. Reproductive health services in Pakistan for women in rural areas are being provided by a network of basic Heath Units (BHUs), Rural Health Centers (RHCs) and in urban areas through Maternal and Child Health $(\mathrm{MCH})$ centers.

Lahore is big city with 10 million population having $50 \%$ female with $45 \%$ of child bearing age (CBAs), to cater the $\mathrm{MCH}$ services in addition to five tertiary and two secondary care hospitals, there are $52 \mathrm{MCH}$ centers in 
public sector. In private sector many hospitals are providing $\mathrm{MCH}$ services to target population.

The cervical cancer deaths reported by Global Burden of Diseases for Pakistan in 1990 were 1106 with 2.02 rates per 100,000 females. In 2012 number of deaths was reported 1918 with 2.20 rates per 100,000 females of all age groups (16).

For cervical cancer pre malignant stage is well defined and tests are available to diagnose it and treatment is possible and available. The developed world has witnessed a significant decrease in of cervical cancer incidence and prevalence. Unfortunately, the situation is very different in the developing countries. Lack of infrastructure and resources does not allow Pap smear based cytological screening services. Many countries have been using alternative screening strategies using simple technologies without necessitating elaborate and expensive systems, visual inspection with acetic acid (VIA) and the use of Single Visit Approach by see and treat in the same visit is a time tried and feasible option. Human papilloma virus (HPV) is the most common sexually transmitted diseases which causes cervical cancer $(17,18)$.

There are primary and secondary cervical cancer preventions, primary prevention is vaccination. Screening, regular pap smear examinations, safe sex practices, lowering the number of sex partners and quitting the smoking are effective preventive measures (19). At early stage diagnosis of cervical cancer has a very good prognosis and treated well (20). VIA is an effective, inexpensive test and can be performed by a lady health visitor, by doing the vaginal speculum examination, they would apply dilute acetic acid (3-5\%) to cervix, and can see abnormal tissue temporarily appears white after exposed to acetic acid (21).

The National Maternal and Neonatal Child Health (NMNCH) programme was started in Pakistan in 2006. Its goal was to improve the maternal and child health in the country, predominantly poor community, by strengthening on going and new interventions In each province provincial implementation units were established in 2007 , which were responsible planning and execution, through district units. Districts units were headed by Executive Districts Officers, supported by public health specialists and social mobilizers. For close community services a lady health workers were appointed in 1994. In 2005 they were attached to health facilities for referral of complicated deliveries, serious children and family planning. They also disseminated health education massages regarding metrnal and child health (22).

\section{Purpose of the study}

The knowledge and clinical skills of the Lady Heath Visitors of $\mathrm{MCH}$ centers of city government of Lahore, were assessed in order to plan a training program for them. For the purpose Girls and Women Health Initiative (GWHI) an International Non- Governmental Organization based at Lahore conducted this study that an evidence based training may be arranged for the Lady Health Workers to perform VIA for early diagnosis and prompt treatment to avoid the development of cervical cancer.

Study objective was:

- Assessment of knowledge and practice of LHWs regarding Cervical cancer

\section{Methods}

Health facility based cross-sectional study was done from 11th -31st December, 2016 in Lahore. Total $52 \mathrm{MCH}$ centers headed by LHVs are working in the city to provide the basic maternal and child health services in the community. Hence; all LHVs were selected to participate in the study. All participants (100\%) were selected using censes sampling technique and were interviewed at their center by a qualified/trained research associate.

After getting ethical approval from IRB (Institutional Review Board) of the Contech School of Public Health, Lahore, study was commenced. Written informed consent was obtained. Data were gathered through in depth interview on pretested questionnaires.

The questionnaire was developed in english and Urdu, which covered demographic information, sexual risk profile, knowledge, and practice, HPV vaccination for cervical cancer prevention. Participants were also asked whether they have been tested HPV.

Data were entered in excel sheets and then exported to SPSS V 20 and did analysis, P-value was calculated and $<0.05$ was considered significant statistically.

\section{Results}

$52 \mathrm{MCH}$ centers in Lahore were surveyed and drop out was zero. Respondents were Lady Health Visitors (LHVs), all (100\%) had basic knowledge about cervical cancer. As far as the types of speculums used in Gynecology examination, $96.1 \%$ of the respondents were aware and rest were not aware about the types of speculum used in Gynecological examination. 94.2\% of respondents were aware regarding one indication of cervical cancer, 92.3\% were aware about indication for doing a speculum examination and $82.7 \%$ told that they were able to detect cervical cancer during routine Gynecology examination and $82.7 \%$ reported that they had been taught how to do speculum examination. $76.9 \%$ were agreed that they were confident to perform speculum examination and do speculum examination one in week on an average and rest $(24.1 \%)$ do not perform a speculum examination. As far as the knowledge about the availability of the test in Pakistan, the more than fifty $(51.9 \%)$ of the respondents said that Cervical cancer diagnostic tests are available, whereas only $50 \%$ of the respondent had knowledge about HVP test. Regarding the smoking or drinking cause the cervical cancer, $69.2 \%$ of the respondents did not agree and rest of $(30.23 \%)$ of the respondents agreed with this statement that smoking or drinking can cause cervical cancer. The majority (69.3\%) of the respondents told that there is no bad effect of overweight (BMI over 25 kg-m 2) 
on cervical cancer and $30.77 \%$ of the respondents were of opinion that there is bad effect of overweight. The $28.8 \%$ respondants had knowledge regarding human papilloma virus (HVP) infection, $71.2 \%$ of the respondent had no knowledge about HVP.

The majority $73.1 \%$ of the respondents were not taught about cervical cancer when they were student and only $26.9 \%$ agreed that they were taught during the study. Only $25 \%$ were aware about Pap smear test. Most lady health visitors had a view that for smear testing/ sample collection is the procedure for doctor and $90 \%$ LHVs never had referred a patient for Pap testing. $78.8 \%$ of the respondents had not ever seen a cervical cancer patient and few of them (11.2\%) of respondents had seen a cervical cancer patient. A significant majority (88.46\%) of respondent had not any close relative with cervical cancer; only few had a close relative of cancer patient. The significant majority $(88.5 \%)$ of the respondents did not attend any training on cervical cancer.

Do you Know the causes cervical cancer (CC)? Is it prevalent in Pakistan? Have you heard Colposcopy?

If yes, in wich class?

Are you aware of simple, acetic acid and. Is there any test available cervical cancer. Ever attended training related to cervical.

Do you have any close relative with cencer? Have you ever seen a cervical cancer patient? Are you aware of Pap smear test? Were you taught abour cervical cancer as a. What is HPV infection?

Is there any bad effect of over weight (BMI. Is the som oking/drinking alchol cauases. Are you awear of HPV TE ST? Is there any test available in Pakistan? Do you do speculum ex amsone in a week on. Are you confident to perform a speculum ex am? Have you been taught how to do a seculim

$\mathrm{C}$ an we detect $\mathrm{CC}$ during routine. What are the indications for doing a speculum Can you name one indication? What types of speculums are used in. Do you khow what cervix is?

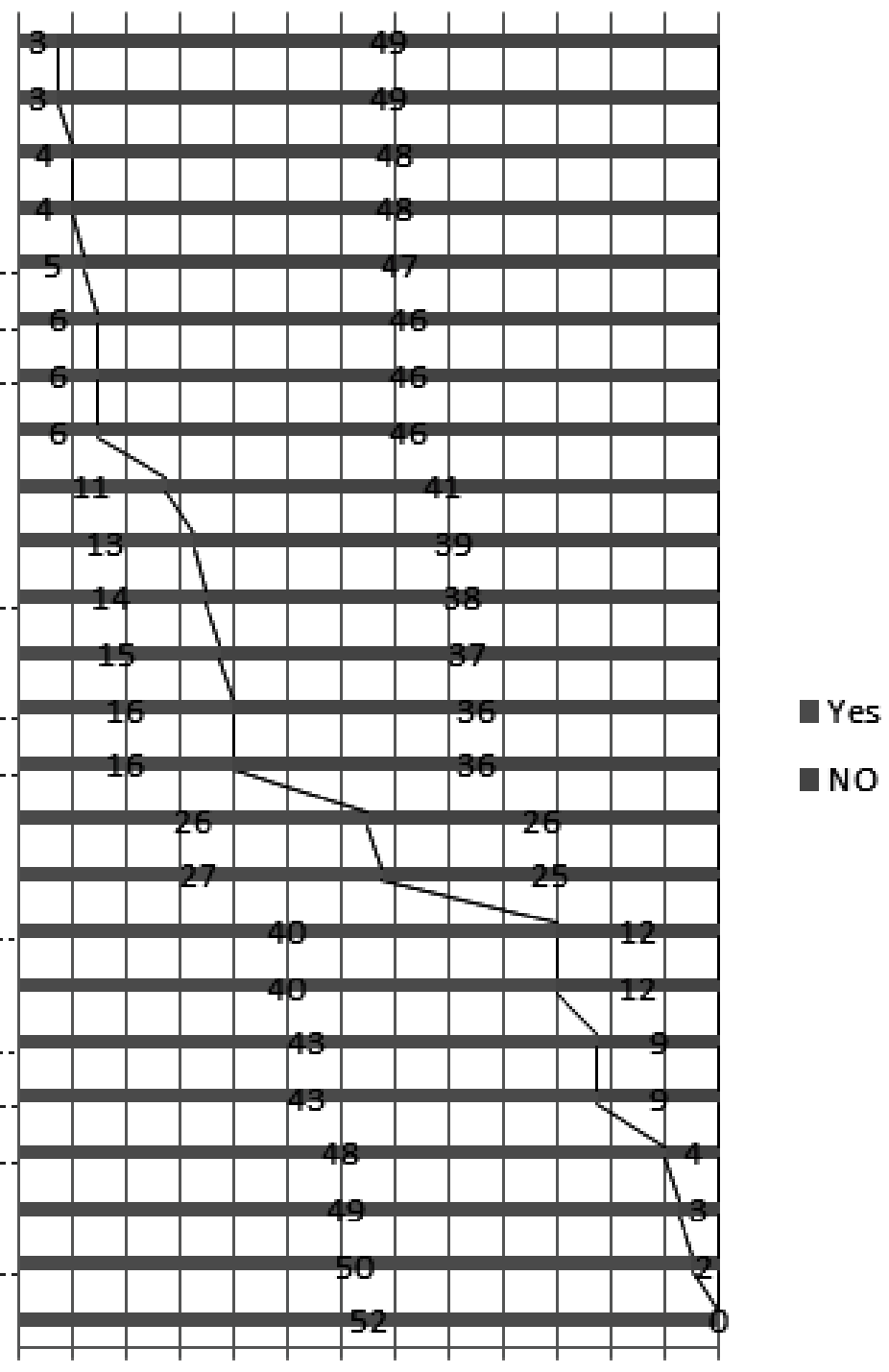

$0 \quad 4 \quad 8 \quad 1216202428323640444852$ Number of Respondants

Figure 1: Knowledge assessment of Lady Health Visitors about Cervical cancer in Public Sector Maternal and Child Health centers in Lahore City, Pakistan

As far as the test availability for cervical cancer diagnosis at pre-cancer stage the majority (88.5\%) of respondents was not aware and remaining (11.5\%) were aware about the test availability for cervical cancer diagnosis. The significant numbers $(90.4 \%)$ of the respondents were not aware of sample, acetic and iodine visual test and few $(9.6 \%)$ were aware, whereas (92.3\%) respondents do not heard about the colposcopy. $94.3 \%$ were of the opinion that cervical cancer is not prevalent in Pakistan and same number was not aware about causes of cervical cancer (Fig 1). 
$58 \%$ of respondents were not aware how common is cervical cancer among gynecological cancer, $23 \%$ told moderate, $13 \%$ said in most common and $6 \%$ told it is least common (Fig 1). What is the mortality rank of cervical cancer amongst gynecological cancer is given in Fig 2, Causes of cervical cancer are shown in Fig 3. Treatment choices employ in cancerous lesions in cervix are explained in Fig 4. Infectious causes of cervical cancer are described in Fig 5, names of causative agent of cervical cancers are shown in Fig 6, route of transmition of the causative agent of cervical cancer are given in Fig 7 and risk factors for developing cervical cancer are described in Fig 8.
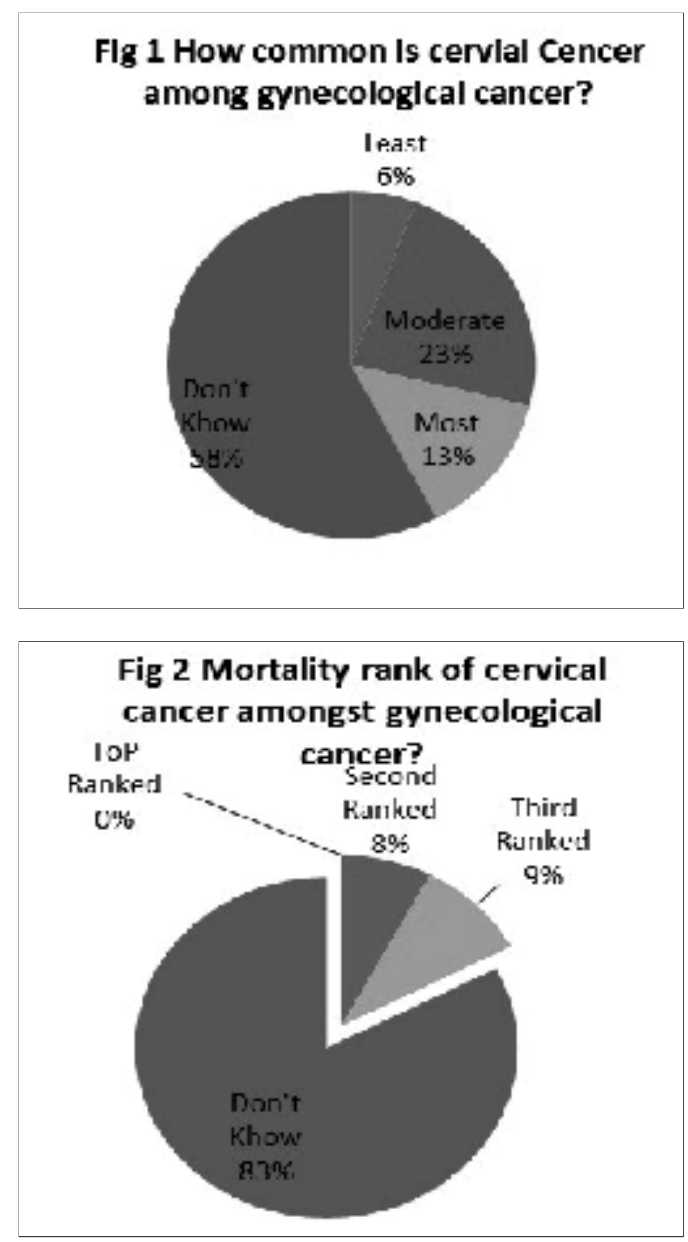

Fig 3 Causes of cervical cencer

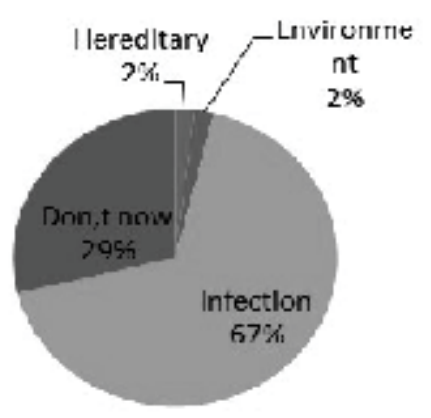

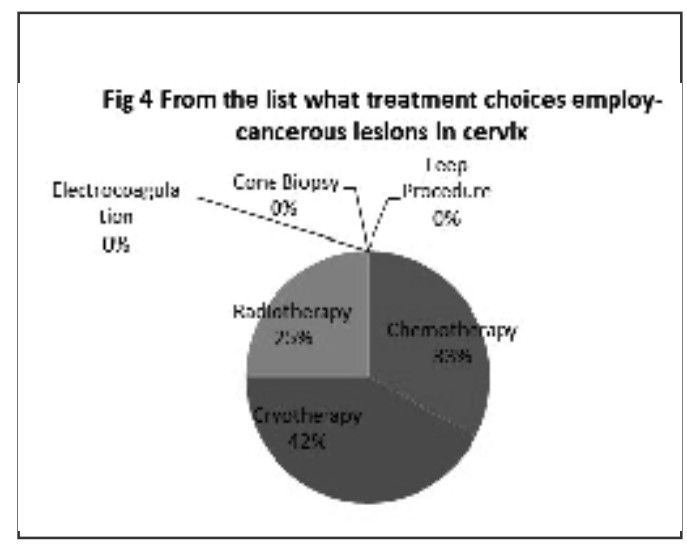

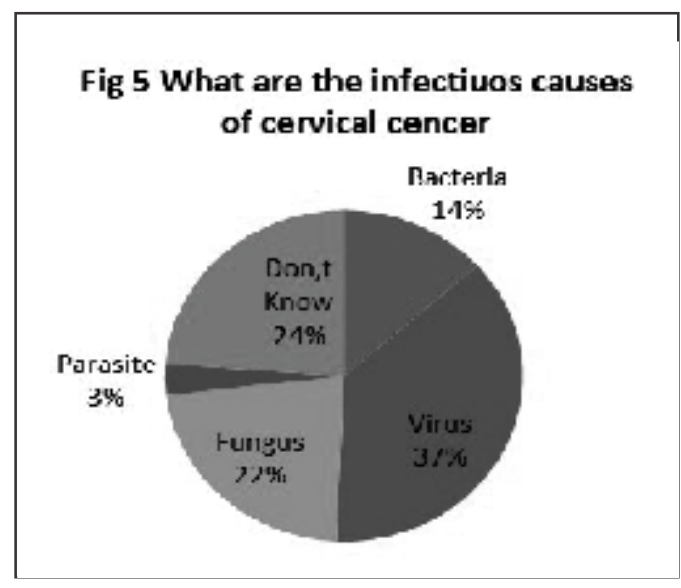

FIg 6 Name the causative agent of cervical cencer

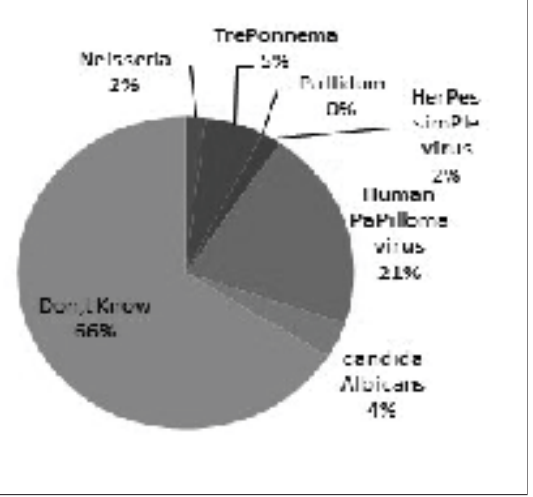

Fig 7 What is the route of transmition of the causative agent of cervical

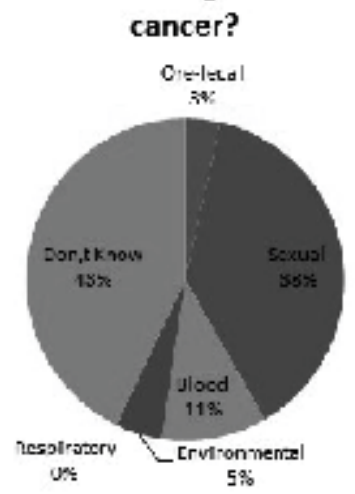

Pakistan Journal of Public Health| Vol. 7, No. 4| December 2017 


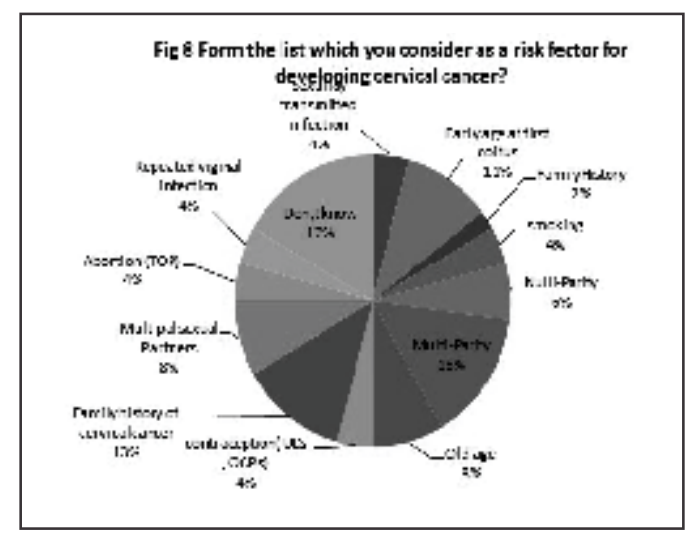

Various questions regarding cervical cancer are given in Fig $9,10,11,12,13,14,15$ and 16

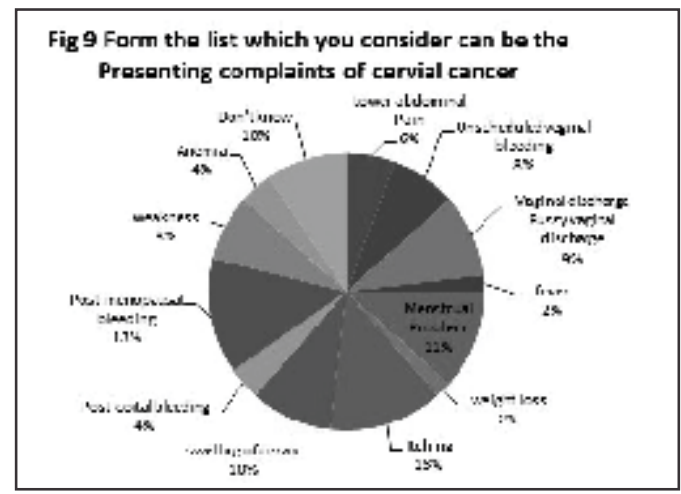

FIg 10 Do you think cenvical cancer can be Prevented $\mathbb{P}$

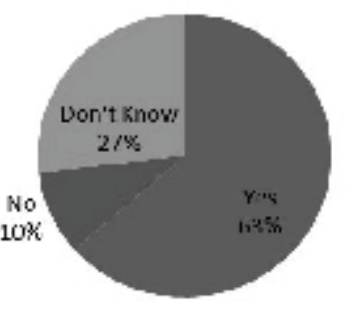

Flg 11 Does the causative agent can caues any other disease?

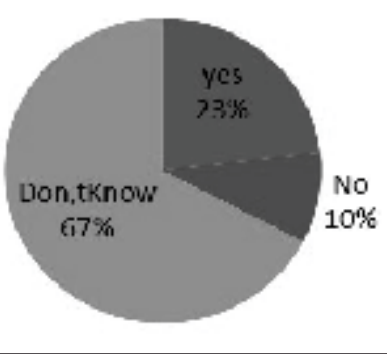

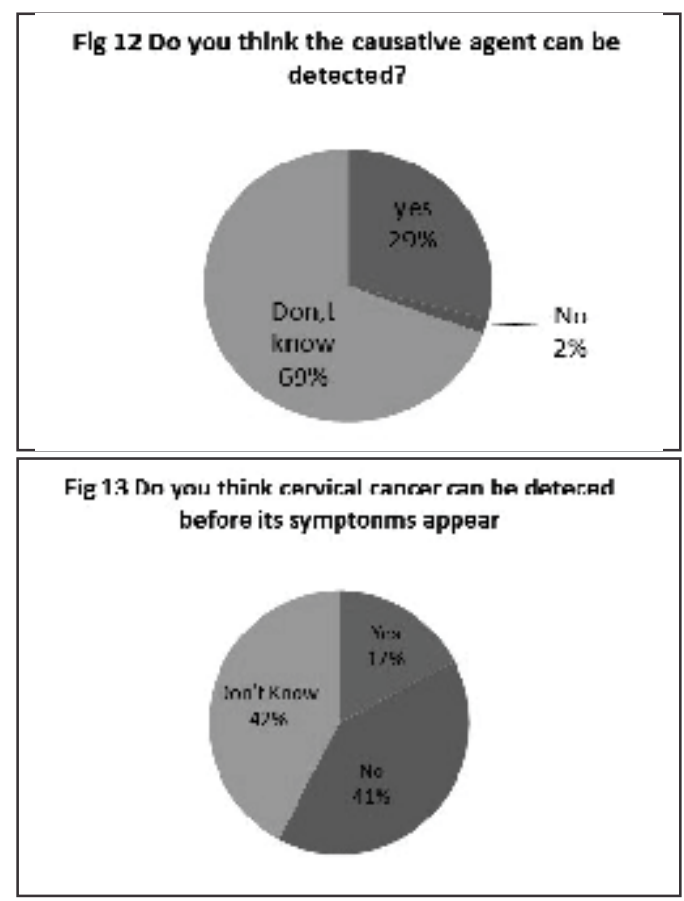

FIg 14 If yes! cervlcal cancer can be prevented trough?

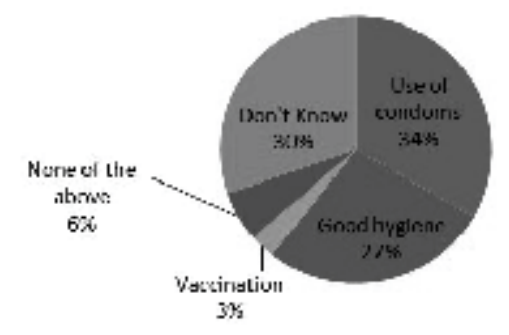

Fig 16 If yes I what techniques are available for its detection?

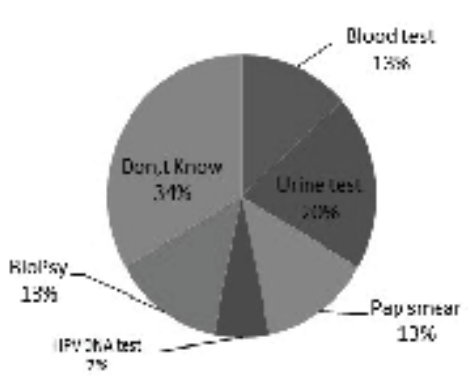

Fig 15 If yes! what disease?

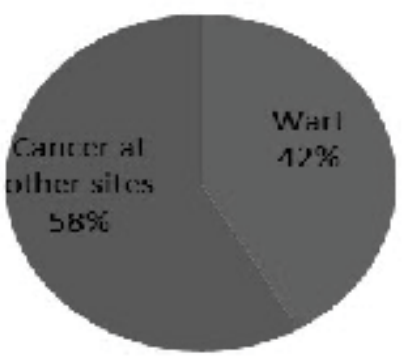




\section{Discussion}

A lot of Global financial and political efforts have been made during the past two to control and prevent the cervical cancer by creating awareness in masses and developing skills of health

providers. But present study showed very disappointing results.

Pre malignant phase of cervical cancer is well defined and tests are available to diagnose it in the pre malignant phase. Treatment is possible and available. Hence there should be no more cervical cancer. The developed world has beheld a significant decrease in incidence of cervical cancer and mortality has also reduced.

Unfortunately, the situation is very different in the study area. Lack of infrastructure and resources does not allow Pap smear based cytological screening services. Many countries have been using alternative screening strategies using simple technologies without necessitating elaborate and expensive systems. VIA and the use of Single Visit Approach by see and treat in the same visit is a time tried and feasible option, GWHI has run a pilot using VIA as cervical cancer is mostly spread through sexually transmitted papilloma virus which common infection of female reproductive canal. The meticulous morbidity and mortality with cervical cancer is not defined in Pakistan because it is an ignored disease in terms of screening and prevention. Inconsistence epidemiological data is available in different studies because of small-scale studies, limited population and dealing with only registered cases.

\section{Conclusion}

Majority of staff was unaware about cervical cancer causes, diagnosis, treatment, and prevention. They were least interested regarding knowledge of cancer and did not meet the minimum standard of any basic health provider.

\section{References}

1. Knowledge, attitude and practice for cervical cancer prevention and control among women of childbearing age in Hossana Town, Hadiya zone, Southern Ethiopia: Community-based crosssectional study Southern Ethiopia. PLoS ONE . 2015; 12(7).

2. Cervical Cancer Treatment. National Cancer Institute. 2014.

3. Defining Cancer. National Cancer Institute. 2014.

4. Tarney. C. M, Han. J. Postcoital bleeding: a review on etiology, diagnosis, and management. Obstetrics and Gynecology International. 2014.

5. Kumar. V, Abbas. A.K, Fausto. N, Mitchell. R.N. Robbins Basic Pathology (8th ed.). Saunders Elsevier. 2007; 718-721.

6. Kufe. D, Holland-Frei. Cancer medicine. (8th ed.). New York: McGraw-Hill Medical. 2009;1299-1308.

7. Dunne. E.F, Park. I.U. HPV and HPV-associated diseases. Infectious Disease Clinics of North
America. 2013; 27 (4): 765-778.

8. FDA approves Gardasil 9 for prevention of certain cancers caused by five additional types of HPV". U.S. Food and Drug Administration. 2014.

9. Human Papillomavirus (HPV) Vaccines. National Cancer Institute. 2014.

10. Tran. N. P, Hung. C. F, Roden, R, Wu. T.C. Control of HPV infection and related cancer through vaccination. Recent Results in Cancer Research. 2014; 193: 149-171.

11. Cervical Cancer Prevention . National Cancer Institute. 2014.

12. World Health Organization . Fact sheet No. 297: Cancer. 2014.

13. World Cancer Report. World Health Organization. 2014; 1(1).

14. Canavan. T.P, Doshi. N.R. Cervical cancer. Am Fam Physician. 2000; 61(5): 1369-1376.

15. Charles. J, Carraher. E. Carraher's polymer chemistry (Ninth ed.). Boca Raton: Taylor \& Francis. 2014; 385.

16. Parkin. D.M. International agency for research on cancer, International Association of cancer registries. Cancer incidence in five counties. Lyon France. IARCP Press, 2005.

17. A Cross Sectional Study on Knowledge, Attitude and Practice related to Human Papillomavirus Vaccination for Cervical Cancer Prevention between Medical and Non -Medical Students in Hong Kong. 2017. DOI:10.22034/APJCP. 2017.18.6.1689

18. http://www.jpma.org.pk/full_article_text.ph44. ht4.http://www.hpvcentre.net/statistics/

19. http://www.cancer.net/cancer-types/cervicalcancer/screening-and-prevention

20. WHO. Comprehensive cervical cancer prevention and control: a healthier future for girls and women, Geneva, Switzerland, 2013.

21. http://can-mnch.ca/wp-content/uploads/2013/ 09/National-Maternal-Newborn-and-Child Health-Programme.pdf

22. Brief of the National Maternal, Neonatal and Child Health Program. 2009. http://www.who.int/ pmnch/countries/pakistanmnchplan.pdf. 